\title{
Vitisin A Content in Chilean Wines from Vitis vinifera cv. Cabernet \\ Sauvignon and Contribution to the Color of Aged Red Wines
}

\author{
Michael Schwarz, Peter Quast, Dietrich von Baer and Peter Winterhalter
}

\section{Supporting Information:}

Analytical results for the anthocyanin content of the analyzed Cabernet Sauvignon samples from various growing regions (vintages 1999-2002).

\begin{tabular}{c|c|cccccc} 
wine & vintage & \multicolumn{7}{|c}{ anthocyanin content [mg/L] } \\
& & mv 3-glc & peo 3-glc & pt 3-glc & del 3-glc & mv 3-acglc & vitisin A \\
\hline 1 & 1999 & 17.2 & 3.0 & 3.9 & 1.9 & 7.0 & 3.3 \\
2 & 1999 & 23.3 & 5.9 & 5.1 & 4.3 & 4.8 & 2.6 \\
3 & 1999 & 34.6 & 4.6 & 4.5 & 3.0 & 23.5 & 2.9 \\
4 & 2000 & 34.2 & 5.1 & 6.7 & 3.8 & 16.7 & 4.4 \\
5 & 2000 & 16.8 & 3.7 & 3.2 & 1.7 & 6.5 & 1.8 \\
6 & 2000 & 75.0 & 13.9 & 13.3 & 9.6 & 32.1 & 4.8 \\
7 & 2000 & 51.6 & 7.9 & 8.1 & 5.3 & 22.7 & 3.2 \\
8 & 2000 & 56.2 & 13.3 & 8.3 & 5.1 & 29.0 & 1.8 \\
9 & 2000 & 61.9 & 7.9 & 6.1 & 3.8 & 35.2 & 1.5 \\
10 & 2000 & 67.1 & 9.8 & 7.1 & 4.7 & 36.1 & 1.9 \\
11 & 2001 & 57.3 & 11.4 & 9.9 & 6.9 & 31.9 & 4.5 \\
12 & 2001 & 112.8 & 23.7 & 14.2 & 9.2 & 68.3 & 2.0 \\
13 & 2001 & 113.6 & 59.7 & 21.2 & 13.3 & 64.2 & 2.1 \\
14 & 2001 & 67.2 & 8.0 & 6.6 & 4.1 & 40.0 & 2.1 \\
15 & 2001 & 86.9 & 14.6 & 10.1 & 5.7 & 50.1 & 2.4 \\
16 & 2001 & 117.2 & 50.6 & 16.1 & 9.9 & 75.5 & 2.0 \\
17 & 2002 & 93.8 & 36.7 & 22.3 & 20.1 & 51.4 & 8.2 \\
18 & 2002 & 100.8 & 23.5 & 17.3 & 13.3 & 53.6 & 3.3 \\
19 & 2002 & 149.7 & 17.8 & 23.0 & 16.3 & 72.6 & 4.3 \\
20 & 2002 & 177.3 & 26.5 & 26.2 & 20.0 & 100.0 & 4.8 \\
21 & 2002 & 135.8 & 14.0 & 18.0 & 11.1 & 88.8 & 3.4 \\
22 & 2002 & 139.8 & 16.8 & 20.5 & 14.4 & 62.2 & 3.7 \\
23 & 2002 & 99.3 & 29.6 & 23.7 & 22.9 & 52.4 & 9.8 \\
24 & 2002 & 99.4 & 22.6 & 22.4 & 20.8 & 60.2 & 9.5 \\
25 & 2002 & 92.9 & 12.4 & 11.8 & 8.8 & 34.8 & 2.2 \\
& & & & & & &
\end{tabular}

